\title{
EXPERIMENTAL AND THEORETICAL STUDY TO ASSESS THE DYNAMIC IMPACT LOAD ON R.C BRIDGE
}

\author{
Yasser El-Hakem \\ Construction Research Institute, National Water Research Center, Egypt.
}

\begin{abstract}
There are a lot of bridges in Egypt; most of them are used to cross the River Nile or its branches and also to cross the streets to reduce the traffic jam. Due to some problems in the bridge itself or in the road after the bridge, it is required to reduce the velocity of vehicles on the bridge. In many cases obstacles are constructed on the bridge to reduce the velocity of the vehicles. These obstacles cause impact forces in the structural elements of the bridge. Also, due to the rough pavement or due to the bad maintenance of the expansion joints, the impact forces happen when the vehicles pass over the bridge. In this research the vibration responses of a typical R.C bridge, due to truck passing an obstacle on the bridge, were measured using accelerometer transducers connected to a data logger system. Signal processing operations were carried out on the recoded signals to enhance the data quality and to obtain the velocity and displacement from the acceleration response. Finite element model was developed for the bridge to evaluate the effect of vibration. The numerical model was subjected to the real recorded signals (displacement response). The stresses due to these vibrations were calculated and compared to the original stress of the bridge due to static loads. Then, an oscillator beam model was used to model the bridge, the obstacle, and the truck taking into consideration the interaction between them. The results of this model were compared to that obtained from the measured response to assure that the stresses due to the experiment are matched with that obtained from the oscillator beam model. Then a parametric study was performed to study the effect of the obstacle height, the wheel load, and the span of the bridge on the results. The impact factor obtained from the Egyptian Code for Loads was compared to that obtained from the numerical results to investigate the excessive stresses induced in the bridge due to the existence of an obstacle on the bridge. As a result of this study, recommendations and guidelines were suggested.
\end{abstract}

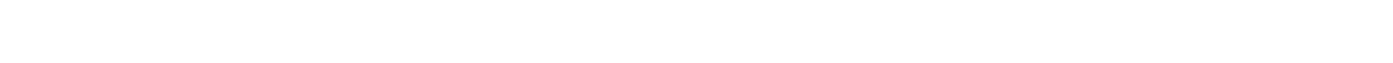

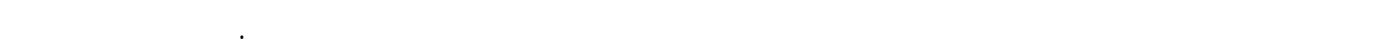

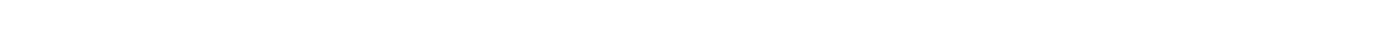

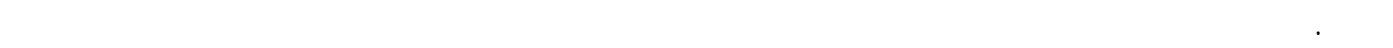

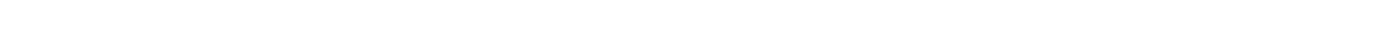

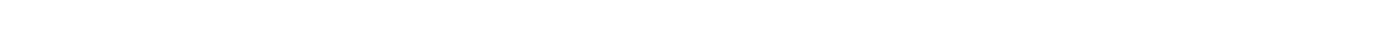

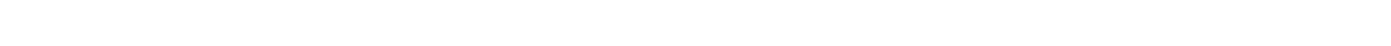

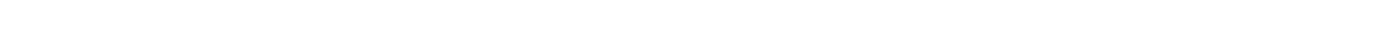

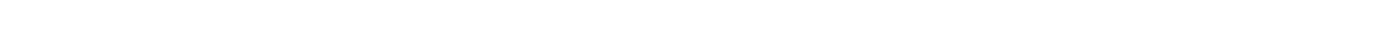

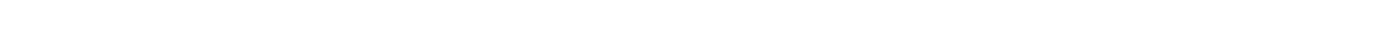
الالحمل المختلفة على المقبلت الصناعية .

Keywords: Impact factor, Bridges, Surface roughness, Obstacle 


\section{INTRODUCTION}

Vibrations induced by truck passing over an obstacle on a bridge, passing rough pavement (as shown in Fig. 1), or passing rough expansion joints may cause excessive stress in the structural elements of the bridge than that considered in the design.
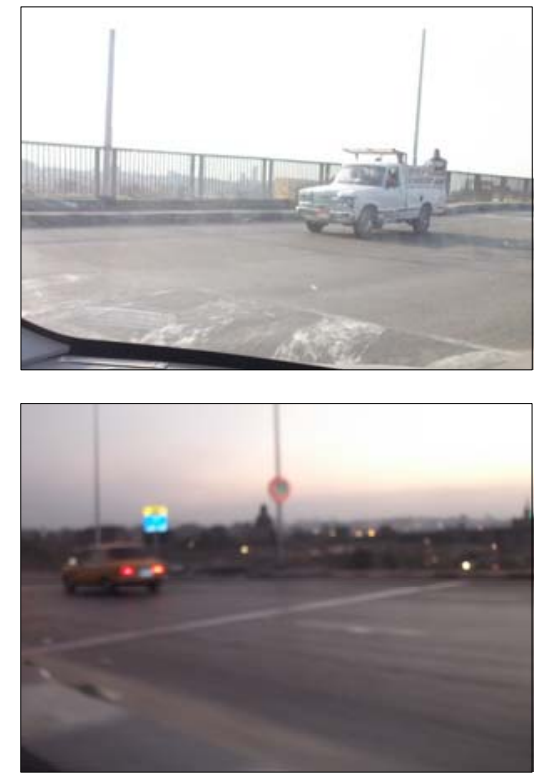

a) Photos for El-Tunsi Bridge

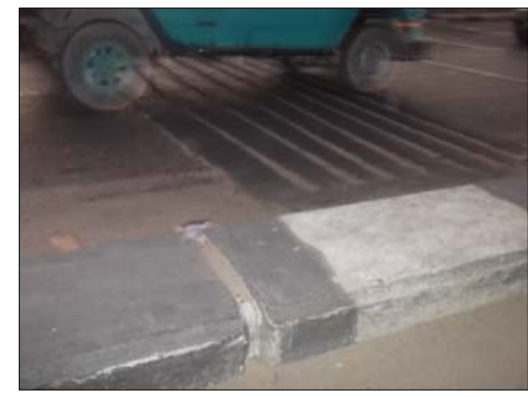

b) Photo for King Khaled bridge

Fig. 1: Photos for two bridges on the Autostrad road in Cairo.

This research attempts to assess the impact effect when a truck passes an obstacle on the bridge and compares it with that calculated according to the Egyptian code. Previous studies were done to study the effect of vibration on bridges. Malajaars [1] measured and evaluated the dynamic response of a vehicle passing a bridge near the expansion joints. Jin-Hak Yi, et. al, [2] evaluated load carrying capacity using loading tests with controlled heavy weight, the deflection of the structural members loaded by the controlled vehicles are measured and analyzed. Using the measured data, deflection correction factor and impact correction factor are calculated. Ravindra K. G., et. al, [3] presented the results of an analytical study undertaken on standard railway bridges which suggested that dynamic analysis of bridges is required to be done for design of bridges for high speeds. Jeng-Hsiang L., et. al, [4] developed a spectral approach for evaluating the dynamic vehicle load due to the passage of a vehicle moving at constant speed along a rough bridge surface.

\section{TEST SETUP}

The dynamic responses of a typical R.C bridge in Damietta were measured. The vibrations were recorded by accelerometers attached to the main girders at specific locations. The span of the bridge is $11.00 \mathrm{~m}$. The structural system of the bridge consisted of four simply supported R.C girders rested on two piers.

Six accelerometers were mounted to the bottom of each of the 2nrd and 3rd girders of the bridge to measure the vibrations of the bridge. These accelerometers were distributed all over the span length of the girders. Figure 2 shows the bridge, truck, and the obstacle used in the research, whereas Fig. 3 shows one of the accelerometers attached to the bridge.

When performing the impact loading test, the front wheels of the test vehicle were dropped from the wood block of about $15 \mathrm{~cm}$ height. The impact points were the mid-span of the bridge. The wheels of one side of the truck were moving along the third girder.

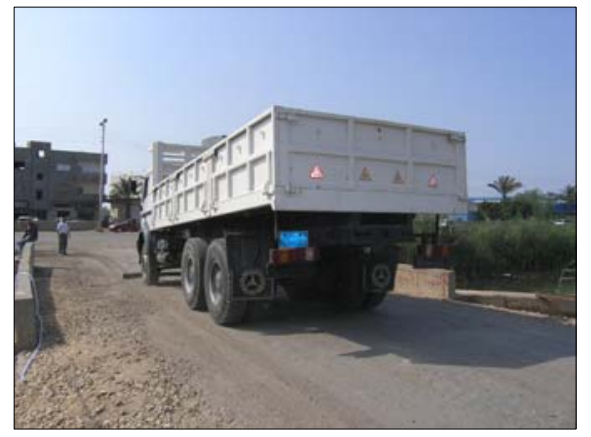

Fig. 2: Photo for the truck and the obstacle on the

bridge.

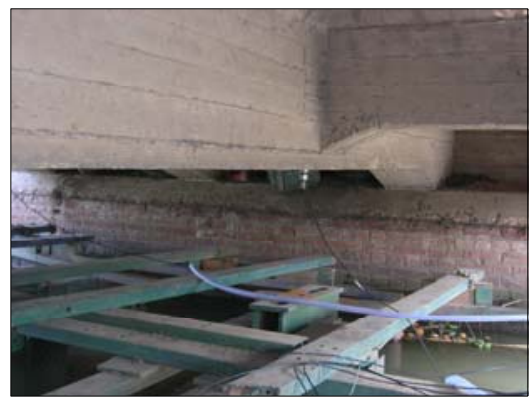

Fig. 3: Accelerometer attached to the bridge. 
The vibrations induced by a truck passing an obstacle were recorded. Seven records were collected each of them was 6 seconds long.

\section{DATA PROCESSING}

The response of the bridges was recorded by accelerometers since the acceleration is the simplest quantity to measure and the most used quantity in engineering studies. However, for the purpose of this study knowledge of velocity response and displacement response is necessary. Numerical integration methods were applied to the recorded acceleration wave form to obtain velocity and displacement responses. Curve fitting using 5th order polynomial was using to correct numerical integration errors when integrating acceleration and velocity.

To simulate the vibration effect the displacement wave form was used as a dynamic load which was applied on the bridge finite element model.
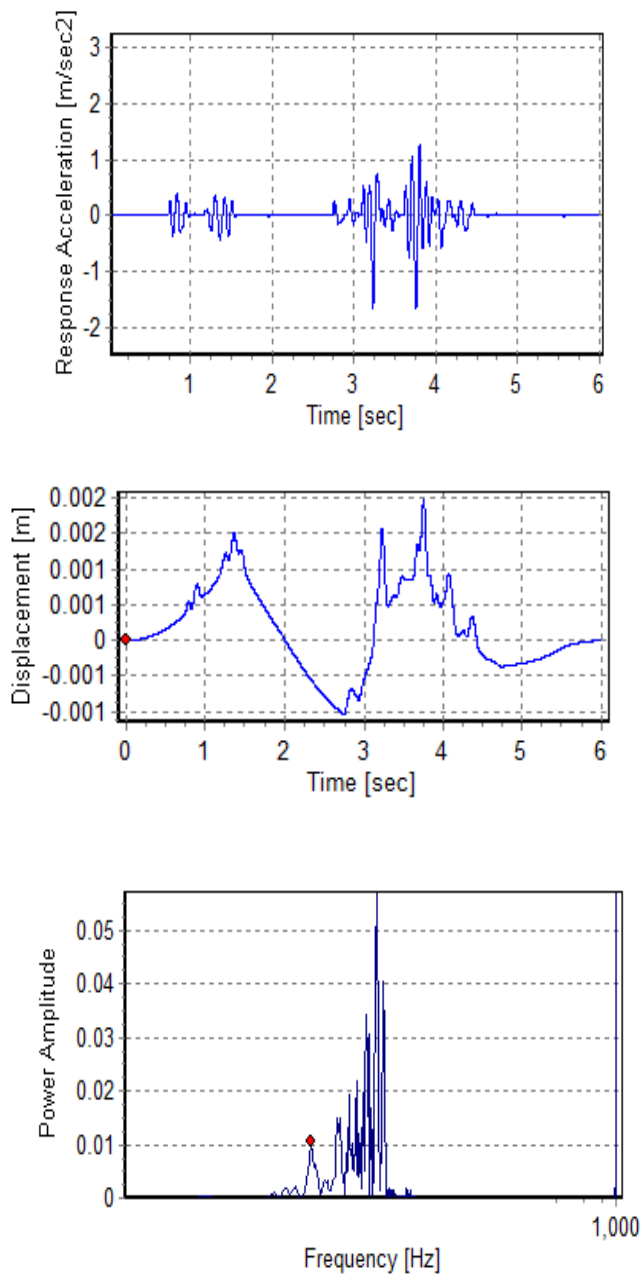

Fig.4: Sample of measured signals and processed data.
Two records with 6 sec. each with average values compared to other records were selected from the 7 records collected to the bridge. The acceleration wave form was subjected to numerical double integration to obtain velocity and displacement responses.

The average power spectrum was calculated for the bridge to determine its fundamental frequency. The results are shown in Fig.4. The fundamental frequency obtained from the average power spectrum was $2.4 \mathrm{~Hz}$.

\section{FINITE ELEMENT MODELS}

The distance between the main girders of the bridge is $2 \mathrm{~m}$. The configuration of the truck used in the research is shown in Fig. 5 .

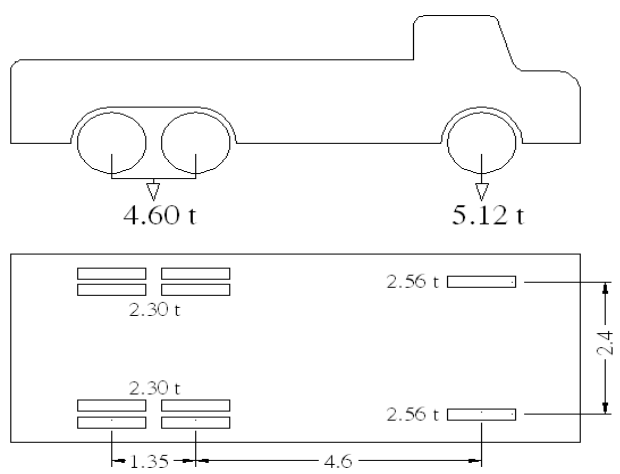

Fig.5: Vehicle configuration.

Finite element numerical model was developed for the bridge using Sap2000 Non-linear package [5]. The deck was model by frame elements with stiffness equivalent to the main girder and the slab, since the wheels of one side of the truck are moving above the 3rd main girder. The frame elements have the dead load carried by the main girder. The displacement time histories for the measured response were applied to the bridge. The bending moments induced in the frame elements due to the displacements time histories (vibrations) were obtained.

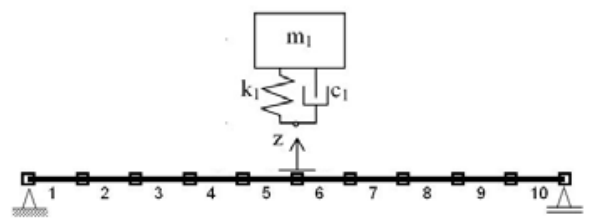

Fig. 6: Oscillator-beam interaction model. 
An oscillator-beam interaction (OBI) model was implemented to the model to take into consideration the interaction between the truck and the bridge. The truck was modeled using spring and damper with mass equivalent to the wheel load. This mass was subjected to free falling with gravity acceleration for a distance equals to the height of the obstacle, before the effect of the spring and damper took place. Since the value of the spring stiffness of the vehicle depends on the mass of vehicle and the vertical frequency, this stiffness was calculated from wheel load of the truck and a vertical fundamental frequency $=3.4 \mathrm{~Hz}$ to represent the truck family [6]. In addition, 30\% critical damping was assumed for modeling the shock absorbers and other energy dissipation in the vehicle.

\section{CALIBRATION OF THE MODEL}

The finite element models were first calibrated with the experimental data to give fundamental frequency matching with the experimental ones. The end conditions of the model were adjusted to reach acceptable values since that it is not pure hinge in the real bridge. The values of the first mode obtained from experimental measurements and numerical model were $2.4 \mathrm{~Hz}$, and $2.5 \mathrm{~Hz}$ respectively.

Also, the values of the maximum moment induced in the main girder calculated from the numerical model when it was exposed to two

measured responses of the truck passing $15 \mathrm{~cm}$ obstacle height were 14.53 m.t, and 17.52 m.t with average value equals to 16.1 m.t. The value of this moment obtained from the finite element oscillator beam model was 15.9 m.t when the wheel fell free for a distance equals to the height of the obstacle.

The calibrated model was used in further analysis to obtain the effect of measured vibrations on the bridges. In this study the bending moment was considered in the analysis as the internal force that represent the impact factor (If) which is typically defined as the ratio of the dynamic plus static effect to the static effect.

\section{PARAMETRIC STUDY}

A parametric study was performed using the beam oscillator finite element model to investigate the effect of the obstacle height, the wheel load, and the span of the bridge. The height of the obstacle was taken $5 \mathrm{~cm}$ (to model pavement roughness), and $10 \mathrm{~cm}$, and $15 \mathrm{~cm}$ (to model obstacles). The wheel load was taken 2.56t (as wheel load for the truck used in this experiment), 5t, and $10 t$ as the wheel load for the 30t and 60t trucks specified by the Egyptian code for Loads [6].

\section{RESULTS}

The additional moments induced in the elements due to the truck plus its impact effect were calculated and divided by the static moment to get the impact factor used in the parametric study. This impact factor was compared to the impact factor given in the Egyptian code for loads [7] which is used to incorporate the dynamic effect of vibrations into the design loads of the bridges. This comparison was done to investigate the reliability of this impact factor for bridges exposed to these types of impacts.

\subsection{Effect of Vehicle Load}

Figure 7 shows the relation between vehicle load and the IF.

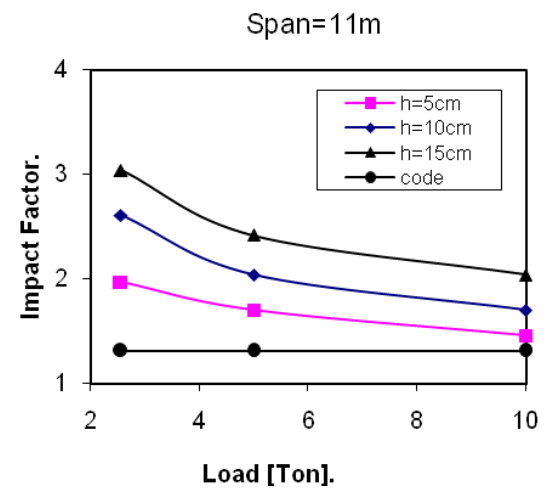

Fig.7: The relation between vehicle load and the IF for $11 \mathrm{~m}$ span.

As shown in this figure, when the wheel load increases, the impact factor decreases. For example; when the span length was $11 \mathrm{~m}$, and for $15 \mathrm{~cm}$ obstacle height, the values of the IF were 3.04, 2.42, and 2.04 for wheel load $=2.56 \mathrm{t}, 5 \mathrm{t}$, and $10 \mathrm{t}$, respectively. These values were higher than that calculated according to the Egyptian Code (by about $132.1 \%$ to $55.7 \%$ ).

The explanation of why the IF decreases with the heavier vehicle load is that, while the dynamic forces increases with the increasing vehicle weight, the static load increases more rapidly with the increasing weight. Thus the ratio of dynamic forces to static 
vehicle load decreases with increasing vehicle weight.

This means that the IF due to the existence of obstacles, rough expansion joints, and surface roughness, has a significant effect on bridges designed to carry light vehicles.

\subsection{Effect of Span Length}

Figure 8 shows the relation between span length and the IF for obstacle height $=15 \mathrm{~cm}$.

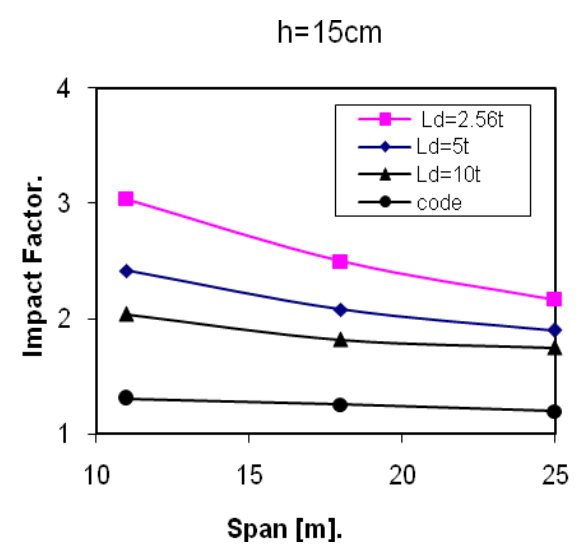

Fig.8: The relation between span length, load and IF for $\mathrm{h}=15 \mathrm{~cm}$.

The results of the parametric study and, also the results calculated according to the Egyptian Code show that when the span length increases the impact factor decreases. For example; when the obstacle height was $15 \mathrm{~cm}$, and for $10 \mathrm{t}$ wheel load, the values of the IF were $2.04,1.82$, and 1,75 for span length $=$ $11 \mathrm{~m}, 18 \mathrm{~m}$, and $25 \mathrm{~m}$, respectively. These values were higher than that calculated according to the Egyptian Code (by about $83 \%$ to $44.4 \%$ ).

The decrease of the IF with the increase of span length happened because the static moment increases with the increase of the span, while the effect of the span length on the dynamic forces was small.

\subsection{Effect of Obstacle Height}

Figure 9, shows the relation between obstacle height and the IF.

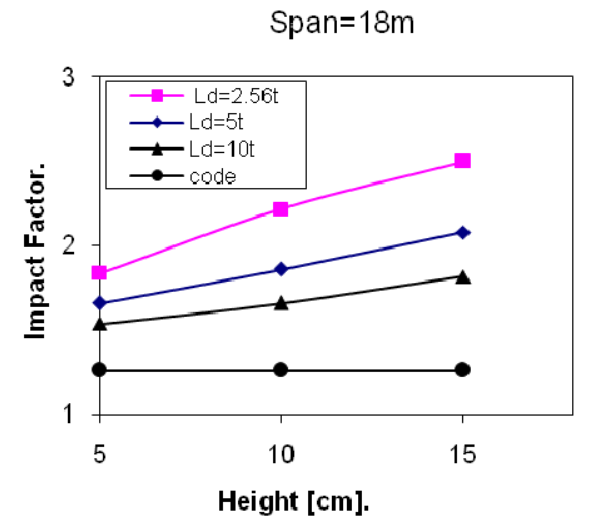

Fig.9: The relation between obstacle height and IF for $18 \mathrm{~m}$ span.

The results show that when the obstacle height increases the impact factor increases. For example; when the span length was $18 \mathrm{~m}$, and for $10 \mathrm{t}$ wheel load, the values of the IF were 1.54, 1.66, and 1.82 for obstacle height $=5 \mathrm{~cm}, 10 \mathrm{~cm}$, and $15 \mathrm{~cm}$, respectively. Also, these values were higher than that calculated according to the Egyptian Code (by about $22.2 \%$ to $44.4 \%$ ). This means that the dynamic impact on bridges designed to carry light vehicles has a significant effect than that designed to carry heavy trucks.

For obstacle height $=5 \mathrm{~cm}$ which represents pavement roughness, the values of the IF in the parametric study were about (from 1.46 to 1.97). These values were higher than that calculated according to the Egyptian Code (by about 12\% to $50 \%)$.

\section{CONCLUSIONS}

Vibrations induced by truck passing obstacle were measured for a typical bridge in Damietta and analyzed to evaluate its effect on the bridge. Finite element model was used to calculate the internal forces in the parametric study. The results of the analysis of this bridge concluded that:

1. When the wheel load increases, the impact factor decreases. The values of the IF were much higher than that calculated according to the Egyptian Code (by about $132.1 \%$ to $55.7 \%$ ).

2. The IF due to the existing of obstacle, the surface roughness, and the rough expansion joints, has a great significant effect on bridges designed to 
carry light vehicles than that designed to carry heavy trucks.

3. For pavement roughness $=5 \mathrm{~cm}$, the values of the IF were higher than that calculated according to the Egyptian Code (by about $12 \%$ to $50 \%$ ).

4. When the span length increases the impact factor decreases. The values of the IF were higher than that calculated according to the Egyptian Code (by about $83 \%$ to $44.4 \%$ ).

5. When the obstacle height increases the impact factor increases. The values of the IF were higher than that calculated according to the Egyptian Code (by about $22.2 \%$ to $44.4 \%$ ).

6. As a result of the research, the specifications which consider the effect of span length only, should take into consideration the vehicle load, the pavement roughness, and condition of the expansion joints when calculating the IF.

\section{REFERENCES}

[1] Maljaars J., Waarts P.H., Leenderts, and Hoogvelt, J.S.,"Dynamic Increment Factor in Modular Expansion Jjoints of Bridges under Heavy Traffic Loading", $7^{\text {th }}$ International Symposium on Heavy Vehicle Weights \& Dimensions, Delft., The Netherlands, June 16 20, 2002.

[2] Jin-Hak Yi, et. al, "Structural performance evaluation of a steel-plate girder bridge using ambient acceleration measurements", Structures and Systems, Vol. 3, No. 3, 2007, pp. 281-298 country

[3] Ravindra K. G., "Effect of Incraesing Spead in Dynamic Impact-An Analytical Study on Standard Steel Girder",IRICEN Journal of Civil Engineering, Sept., 2009, p302-318. country

[4] Jeng-Hsiang L., and Cheng-Chiang W.," evaluation of Dynamic Vehicle Load on Bridge Decks", Journal of the Chinese Institute of Engineers, Vol. 27, No. 5, 2004, pp. 695-705.

[5] Computers and Structures, Inc., "Sap2000 Nonlinear Ver. 10 Reference Manual”, Berkeley, California, USA, July 2005.

[6] Yang, Y. B., Lin C. W., \& Yau J. D. "Extracting bridge frequencies from the dynamic response of a passing vehicle", Journal of Sound and Vibration 272, No.3-5(May 6), 2004, pp.471-493.
[7] "Egyptian Code for Calculation of Loads and Forces in the Construction Works", Housing and Building National Research Center, Egypt, 1993. 